\title{
DIÁLOGOS TRANSVERSAIS: A HISTÓRIA INDIGENA E A EDUCAÇÃO
PATRIMONIAL NO PROTAGONISMO DAS AÇÕES
EDUCATIVAS NO TRIÂNGULO MINEIRO.
}

Gabriela Gonçalves Junqueira

Doutoranda em Antropologia Social pela Universidade Federal de Goiás (UFG). Antropóloga da equipe de Educação Patrimonial da Fundação Araporã. Professora da Rede Estadual de Ensino de Minas Gerais. Pesquisadora no Grupo de Estudos e Pesquisas em Arqueologia, Etnologia e História Indígena (GEPAEHI), da Universidade Federal de Uberlândia.

Daniella Santos Alves

Doutoranda em Antropologia Social pela Universidade Federal de São Carlos (UFSCar). Antropóloga da equipe de Educação Patrimonial da Fundação Araporã. Professora da Rede

Estadual de Ensino de Minas Gerais. Pesquisadora no Grupo de Estudos e Pesquisas em Arqueologia, Etnologia e História Indígena (GEPAEHI), da Universidade Federal de Uberlândia.

resumo: o presente trabalho é resultado de um projeto de educação patrimonial desenvolvido nas cidades de Canápolis e Monte Alegre de Minas região do Triângulo Mineiro, Minas Gerais. As ações educativas foram desenvolvidas num processo de experimentação etnográfica inserido num projeto macro de licenciamento ambiental. Tais ações possibilitaram um despertar do saber e da valorização da memórias, culturas e heranças regionais, especialmente, dos povos indígenas. Esse contato possibilitou uma desnaturalização de imagens cristalizadas e genéricas destes povos e viabilizou a importância do reconhecimento das identidades e patrimônios materiais e imateriais dos municípios. Para tal empreendimento contamos com o diálogo entre escola, universidade e comunidade, ou melhor, na tríade indissociável do ensino, pesquisa e extensão.

Palauras-chave: Educação Patrimonial, História Indígena, Patrimônios. abstract: The present paper results from a heritage educational program developed in the cities of Canápolis and Monte Alegre de Minas situated in the Triângulo Mineiro region, Minas Gerais. The educational activities were undertook in an experimental ethnographic process integrated in a macro level environmental licensing project. Those actions enabled an awakening of knowledge and the valorization of the region's memories, cultures, and heritage, particularly form indigenous people. This contact enabled to demystify the reified e generic portraits of those populations and facilitated the recognition of the importance of the identities and the material and immaterial heritage of the cities. For this aim, we established a dialogue involving school, university and community, or better put, the indivisible triad of, teaching, research and university extension.

Key-words: Heritage Educational Program; Indigenous History; Heritages. 


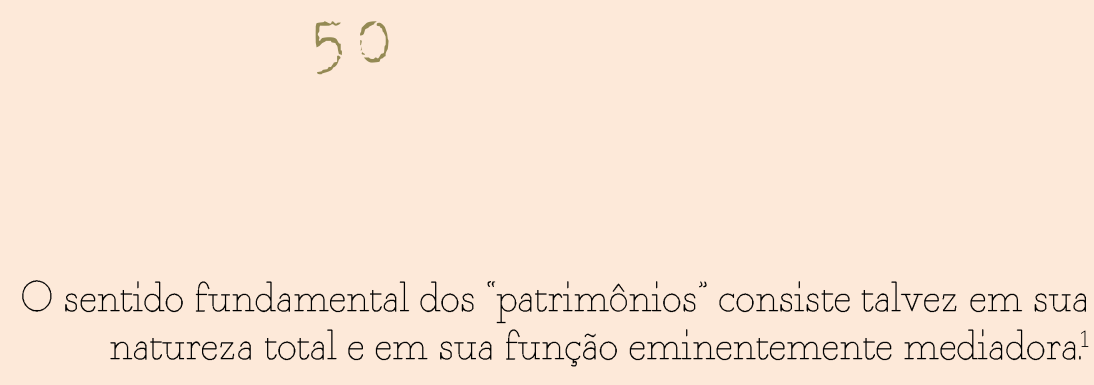

natureza total e em sua função eminentemente mediadora.

\section{introdução}

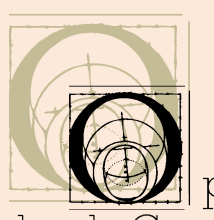

presente artigo é resultado de uma intervenção patrimonial nas cidades de Canápolis e Monte Alegre de Minas, na região do Triângulo Mineiro, no Estado de Minas Gerais. As ações educativas foram propostas por meio da necessidade das pesquisas arqueológicas desenvolvidas no cenário de licenciamento ambiental2 da Fazenda Pirapitinga/MG.

Para tal, é necessário não somente relatar a imersão etnográfica no campo das cidades, mas também as reflexões no âmbito da educação patrimonial e suas variadas possibilidades na prática. Com a intenção de valorizar a história indígena, dando proeminência a identidade e a sua cultura regional demonstramos as expectativas e os resultados que essa experiência nos proporcionou enquanto antropólogas no campo da Educação.

Em meados do ano de 2017, nós da equipe de educação patrimonial composta também pelo Arqueólogo Dr. Robson Antônio Rodrigues fizemos um primeiro contato com a Casa de Cultura de Canápolis - MG. Nesse primeiro contato localizamos na complexidade de informações premissas que versavam sobre a história da cidade também como sobre o formato como eles organizam o ensino dos patrimônios históricos - materiais e imateriais. Em meio a este ambiente elaboramos um plano de meta para que, junto a Casa da Cultura e a prefeitura da cidade, realizássemos ações de educação patrimonial sob três prismas que se completavam mutuamente.

\footnotetext{
1 GONÇALVES, José Reginaldo Santos. Ressonância, materialidade e subjetividade: as culturas como patrimônios. Horizontes Antropológicos, Porto Alegre, ano 11, n. 23, p. 10. jan/jun 2005.

2 Segundo o Instituto Brasileiro do Meio Ambiente e dos Recursos Naturais Renováveis (IBAMA), o licenciamento ambiental seria um instrumento da gestão pública que intenciona exercer um certo controle sobre as ações humanas defronte o meio ambiente. Desse modo, busca a justa medida entre desenvolvimento econômico e a segurança dos ecossistemas tanto em níveis físicos e bióticos, quanto nos planos sócio, econômico e cultural. Nestes três últimos planos que nossa ação tem maior relevância. Isso porque as ações educativas da equipe de educação patrimonial, entra no plano de um licenciamento para mostrar a comunidade e a empresa contratante a relevância de uma dada cultura regional, bem como sua riqueza material e imaterial.
} 
A primeira ação que foi também concomitante as demais seria a produção de um documentário ${ }^{3}$ que envolvesse a importância da educação patrimonial na região do Triângulo Mineiro e Alto Paranaíba a partir de duas cidades centrais, Canápolis e Monte Alegre de Minas. Na ocasião, participamos de conversas inicias e por meio de profícuos diálogos conhecemos os profíssionais da instituição cujo consentimento possibilitou que realizássemos um documentário regional. Tal filmografía buscava a produção de um curta-metragem que conseguisse abarcar e articular a temática do patrimônio, memória e educação patrimonial que será ressaltada com mais detalhes adiante.

A segunda ação e feita sob a cobertura da primeira, seria a oferta de uma oficina para crianças do Ensino Eundamental do ensino Básico em duas Escolas sob - tema "Ofícina de educação patrimonial: reflexões e diálogos sobre a históría indígena da região". A oficina teve como intuito à amplificação das vozes desses indígenas que, como sujeitos históricos, sempre foram sílenciados por um discurso marcado pela colonialidade do poder 4 promovidas pelas frentes de expansão colonial, que desconsideravam completamente a possibilidade de compreensão da cultura destes povos ${ }^{5}$.

Por fim e compilando as ações anteriormente desenvolvidas, apresentamos a ideia de construção de uma cartilha como produto final das ações para que se configurasse junto ao documentário como um material a ser disponibilizado e utílizado tanto por professores como por qualquer membro da comunidade que tenha interesse em tal estudo.

A resposta da Casa da Cultura de Canápolis foi envolta por entusiasmo e o oferecimento de todo o suporte estrutural que a equipe precisasse. Desse tomo, ficou decidido que iríamos numa segunda visita a cidade realizar as entrevistas com a Coordenadora do Departamento de Cultura e com sua assistente e técnica responsável por organizar todo o acervo e espolio da Casa da Cultura.

Ainda nessa primeira visita e contato inicial com os municípios do interesse em foco, saímos de Canápolis com as datas e atividades previamente decididas e

\footnotetext{
3 Para ter acesso ao material conferir: https: / $w$ ww.youtube.com/watch? $v=e c g g J h 0 l m 6 U \& t=509 \mathrm{~s}$

${ }^{4}$ QUIJANO, A. Colonialidade do poder, eurocentrismo e América Latina. In: LANDER, Edgardo (org). A colonialidade do saber: eurocentrismo e ciências sociais. Perspectivas latinoamericanas. Buenos Aires, Colección Sur Sur, pp.118-142, 2005.
}

5 JUNQUEIRA, Gabriela Gonçalves. O visível e o invisível nas relações de contato dos grupos Jê Meridionais: uma análise da caça, guerra e dos rituais funerários como relações de predação, produção e controle dos poderes latentes da alteridade. 2017. 114 f. Dissertação (Mestrado em Ciências Sociais) - Universidade Federal de Uberlândia, Uberlândia, 2017.

6 Para ter acesso ao material conferir: https://issuu.com/fundacaoarapora/docs/cartilhapatrimoniomemoria 
dirigimos nossa atenção para a cidade de Monte Alegre de Minas. Fomos recebidos pelo então coordenador Municipal de Patrimônio Histórico. Tal como aconteceu em Canápolis apresentamos nosso projeto e as intenções de atividades junto ao município. Desse modo, estipulamos datas, horários e organizamos visitas orientadas com o coordenador da cidade sobre os bens da região.

\section{a centralidade do patrimônio nos processos educacionais}

patrimônio cultural enquanto um conjunto de manifestações, realizações e representações de um povo está presente em todas as atividades, fazendo parte do cotidiano e integrando as identidades que determinam os nossos valores. A educação patrimonial, por sua vez, pode ser compreendida, portanto, como a operacionalização didática do patrimônio, isto é, um mecanismo de alfabetização que salienta a seu público a importância de conhecer os bens simbólicos e materiais de uma dada cultura. É por meio dessa ferramenta educacional, cujo conteúdo promove o respeito a diversidade, que podemos dirimir pensamentos e ideias que veiculam o etnocentrismo e a depreciação de outras culturas. Isso porque, se considerarmos as premissas básicas da educação patrimonial vemos que o ato de apresentar e relativizar a pluralidade da vida humana, a partir dos conhecimentos históricos, arqueológicos e antropológicos, construímos comunidades e indivíduos mais adeptos a preservação e valorização de sua cultura. No Brasil, a educação patrimonial tem uma importância sine qua non, isso pois, nossa cultura foi forjada pelo encontro e (des) encontros do histórico choque cultural entre índios, negros e brancos ${ }^{7}$.

Durante séculos, a suposta elevação dos hábitos e costumes europeus, acabaram por marginalizar ou negligenciar a importância sócio histórica da cultura negra e indígena. O espelho narcisista de países centrais da Europa arou um terreno cujas sementes e plantas expressariam, apenas, o produto cultural de alguns povos. As consequências de tais atos registram-se no emudecimento elou desconhecimento da complexa origem de nossa cultura. Tal negligenciamento pode ser visto nas escolas - âmbito essencial na construção de um cidadão - uma vez que só recentemente que promulgou-se leis (10.639/03 e 11.645/08) que estabelece nas diretrizes e bases da educação nacional, a inclusão na rede de ensino a obrigatoriedade da temática História e cultura afro-brasileira e indígena.

\footnotetext{
${ }^{7}$ Os termos índio, negro e branco não se traduzem em uma suposta pureza étnica e nem resumem a real diversidade cultural e societária do Brasil. Todavia, mesmo ciente de suas imprecisões têm a vantagem de indicar a posição diferenciada que esses coletivos têm e tiveram no contexto sociopolítico, econômico e cultural do Brasil.
} 
Nesse tomo, a educação patrimonial torna-se uma ferramenta imprescindível para corroborar no efetivo conhecimento e relativização da diversidade cultural de um país como o nosso. Manter viva a memória de um povo, região ou grupo bem como sua história e importância é fundamental para acicatar nas alunas e alunos a real construção da identidade brasileira.

Para a consolidação de temáticas que englobe a educação patrimonial, foi lançado através do IPHAN, em $1999^{\circ}$ o Guia Básico de educação patrimonial O guia amplifica as possibilidades para desenvolver tanto na escola como na comunidade ações nas quais se pode tocar a sensibilidade e o conhecimento para manter a memória e a cultura viva.

Nos Parâmetros Curriculares Nacionais (PCNs), está prevista a temática da educação patrimonial para o Ensino Fundamental por meio dos temas do meio ambiente e da pluralidade cultural, e são estes temas que se chama de transversais, os caminhos que possibilitam o diálogo interdisciplinar para tratar-se de questões referentes ao patrimônio cultural. Os objetos patrimoniais, são uma possibilidade interessante pois permite por parte dos educadores ultrapassarem os limites muitas vezes propostos pelos currículos, bem como o aprendizado de habilidades importantes no que tange ao conhecimento e ao sentimento de pertencimento dos discentes.

Porém, as escolas sofrem grande carência de material didático para que os professores possam trabalhar em sala de aula, para tanto é necessário que pesquisadores, estejam preocupados em atingir um público cada vez mais amplo de leitores por meio de trabalhos que promove a integração entre escola, universidade e comunidade, ou seja, ensino, pesquisa e extensão.

Nesse sentido, o trabalho que foi desenvolvido nas cidades de Canápolis e Monte Alegre de Minas permitiu que a comunidade valorizasse ainda mais sua identidade e cultura, entendidas como múltiplas e dinâmicas. A relação de pertencimento vistas nos municípios destoa aos olhos do pesquisador uma comunidade envolvida pela sua relação de pertencimento a cultura local, culminando assim, no conhecimento, apropriação e valorização de sua herança cultural, capacitando-os para um melhor usufruto destes bens, e propiciando a geração e a produção de novos conhecimentos e preservação sustentável dos seus bens tombados.

${ }^{8}$ HORTA, Maria de Lourdes Parreiras; GRUNBERG, Evelina, MONTEIRO, Adriane Queiroz. GUIA BÁSICO DA EDUCAÇÃO PATRIMONIAL. Brasília, Museu Imperial/ IPHAN//MinC, 1999. 
No entanto, Horta, et al. (1999)9 nos faz lembrar ainda que o patrimônio cultural brasileiro não se resume aos objetos históricos e artísticos, aos monumentos representativos da memória nacional ou aos centros históricos já consagrados e protegidos pelas Instituições e Agentes Governamentais, são também os artesanatos, maneiras de pescar, caçar, plantar, cultivar e colher, de utilizar plantas como alimentos e remédios, de construir moradias, a culinária, as danças e músicas, os modos de vestir e falar, os rituais e festas religiosas e populares, como as tradicionais festas de Nossa Senhora do Rosário e São Benedito, as Congadas, nos municípios em foco, em que a festa se tornou patrimônio cultural e histórico imaterial.

Os patrimônios, entendidos então enquanto sistemas culturais integrados e dinâmicos ${ }^{10}$ possibilititou a identificação nos municípios tanto de patrimônios materiais quanto imateriais.

$\mathrm{Na}$ cidade de Canápolis enquanto bens tombados temos a presença do conjunto paisagístico da Cachoeira Córrego do Cerrado, do Quadro do Fundador da cidade Coronel José de Paula Gouveia e a Casa da Cultura, lugar onde as ações que valorizam os patrimônios da cidade são pensadas e articuladas dentre os diversos membros que a compõe.

Monte Alegre de Minas, por seu turno, apresenta uma maior presença de bens tombados, sendo distribuídos em bens imóveis e bens móveis e integrados como a Antiga Caixa D’água, Capela de Nossa Senhora da Abadia, Casarão da Família Vilela Parreira, Conjunto Arquitetônico e Urbanístico da Igreja Matriz de São Francisco das Chagas e praças Nicanor Parreira e Luís Dutra Alvim. Fachada da Escola Estadual Tancredo Martins, Monumento aos Retirantes de Laguna e Antigo Forum, Bombardino do Maestro Vidal Reis, Saxofone Alto do Mestre Augusto Reis, Saxofone Alto do Professor Tonato, Trompete Selmer do Dr. Miguel Reis e Tuba Helicom de Eugênio Macedo.

Diante dessa circunstancia as ações da equipe de educação patrimonial buscou provocar reflexões sobre o patrimônio cultural material e imaterial da região em foco do trabalho, no intuito de despertar nas alunas e alunos, professoras e professores e comunidade em geral interesse e curiosidade levando-os a querer conhecer mais sobre eles, e resgatar o sentimento de pertencimento e preservação às referências culturais locais. Para isso, lançamos mão da históría indígena de ocupação da região que engloba o então sertão da farinha podre - atual Triangulo

\footnotetext{
9 Idem.

10 TAMASO, Izabela. Os Patrimônios como Sistemas Patrimoniais e Culturais: notas etnográficas sobreo caso da cidade de Goiás. Revista ANTHROPOLÓGICAS, Ano 19, 26(2):156-185, 2015.
} 
Mineiro e Alto Paranaíba - juntamente com as ocupações históricas dos índios Jê meridionais que ocupavam e preambulavam pela região

A opção pela temática indígena se deu pelo próprio processo do desenvolvimento no pensar a educação patrimonial, visto que em ambos os municípios se relatavam a presença de indígenas na região, mas como algo muito distante e desconhecido ainda. Além disso, o tema vislumbrou colaborar nas escolas para o cumprimento efetivo da Lei 11.645/2008 que dita sobre a obrigatoriedade de se incluir no currículo oficial da rede de ensino a temática "História e Cultura AfroBrasileira e Indígena"11.

Nesse sentido, a relevância do trabalho assentou-se no reconhecimento do patrimônio cultural vindo tanto dos nossos antepassados quanto os que se produzem no presente como expressão de cada geração. E é com todo esse patrimônio, material, imaterial, consagrado e não consagrado ${ }^{12}$ que podemos trabalhar num processo constante de conhecimento e descoberta ${ }^{13}$. Tal herança cultural adquirida pode fornecer informações significativas acerca da história de um país e do passado da sociedade, e por isso acabam por contríbuir na formação da identidade, nas categorias sociais e no resgate a memória, desencadeando assim uma ligação entre o cidadão e suas raízes. Sua preservação torna-se fundamental no que diz respeito ao desenvolvimento cultural de um povo, já que é o reflexo de sua formação sociocultural ${ }^{14}$.

E aqui, a educação patrimonial, por meio das atividades propostas teve como objetivo contribuir com à comunidade para se ter um contato maior e mais estreito com o patrimônio cultural da sua região que até então estava perdido por uma história oficial e oficializante que emudeceu e silenciou a presença indígena e seu protagonismo histórico na região.

Além disso, o trabalho buscou também contribuir com a formação continuada dos docentes, por meio da participação deles nas ações educativas e também pelo acesso a cartiliha que foi resultado deste trabalho, haja vista que tratase de formar mediadores entre o conteúdo inerente ao patrimônio e discentes, que se colocam momentaneamente no papel de educandos do processo de educação

\footnotetext{
${ }^{11}$ BRASIL. Lei 11.645/08 de 10 de Março de 2008. Diário Oficial da União, Poder Executivo, Brasília.

12 Segundo Grunberg (2007) os bens culturais são divididos entre consagrados e não consagrados. Os primeiros são aqueles objetos reconhecidos pela sociedade e protegidos por legislações e leis. O segundo, por sua vez, fazem parte do nosso dia a dia evidenciando, paulatinamente, as nuances e múltiplos aspectos que a cultura viva de uma comunidade pode apresentar.
}

${ }^{13}$ GRUNBERG, Evelina. Manual de atividades práticas de educação patrimonial. Brasília, DF: IPHAN, 2007

${ }^{14}$ ROCHA, Thaíse Sá Freire. Refletindo sobre memória, identidade e patrimônio: as contribuições do programa de Educação patrimonial do MAEA-UFJF. XVIII Encontro Regional ANPUH, 2012. 
patrimonial. Estas ações educativas demandam um trabalho interdisciplinar e a abrangência de formas e conteúdo que atinjam uma exploração racional, eficiente e, ao mesmo tempo, que valorize o potencial do patrimônio ${ }^{15}$.

\section{da imersão aos afetos}

Com alguma precisão nos recordamos do dia que ofertamos a oficina para as alunas e alunos do 6ㅇ ano do Ensino Eundamental da Escola Estadual Márcia Caetano Alves. A escola situada na R. dos Jasmins, 18 - Jardim Eldorado, em Monte Alegre de Minas - MG, tem uma arquitetura próxima as construções mais modernas e se localiza num bairro relativamente remoto. Conta com salas de aulas extremamente arejadas, cadeiras em bom estado e uma decoração baseada na produção intelectual de suas alunas e alunos.

Nossa recepção foi acalorada por perguntas, anseios e curiosidades tanto por parte das alunas e alunos como por parte das professoras que compunham a tinta desse cenário educativo. Estes anseios podem ser pensados pela presença de um grupo de pessoas que não era comum no cotidiano nem das alunas e alunos como tampouco da direção, professoras e professores, secretaria entre outros.

Desse modo, fomos recebidos com a centelha da dúvida e da curiosidade. Fortuitamente, ambientados com a história da região e até mesmo com o caráter indicial utilizado nos recintos, aproximamos desses interlocutores e começamos a desenvolver a atividade. A atividade foi realizada numa sala que comportava mais ou menos vinte discentes e dispunha de um data show. Inicialmente houve as apresentações das alunas e alunos em conjunto com a equipe de educação patrimonial bem como das professoras que acompanhavam a atividade.

A apresentação e exposição inicial dos conteúdos não foram feitas de formas estanques e cristalizadas, houve, com certa frequência a participação das alunas e alunos. Estas, eram acompanhadas, a sua justa medida, de dúvidas e complementos ao assunto conforme sua experiência social e familiar com a temática da educação patrimonial e indígena da região. Os slides compostos quase sempre de imagens e pouco conteúdo escrito tinha o propósito de provocar o que a fotografía permite empreender: a construção e (des)construção de padrões.

15 CARDOZO, Poliana Fabiula; Melo, Alessandro de. PATRIMÔNIO, TURISMO CULTURAL E EDUCAÇÃo PATRIMONIAL. Educ. Soc., Campinas, v. 36, nº. 133, p. 1059-1075, out.-dez., 2015. 
Pensar nos indígenas como grupos que ficam isolados e, portanto, alheios ao ambiente citadino foi a questão central elencada pela turma. Fortuitamente, equacionamos essas certezas tão naturalizadas com dados históricos, arqueológicos e com a oficina de grafismos indígenas. Nesta última, observamos que as alunas e alunos, sentiam a necessidade de se diferenciar dos demais, ou seja, assumindo uma identidade única que os tornassem especiais, tal como os grupos indígenas que estudaram durante o dia. A participação da professora de História destoou aos nossos olhos sobre a presença de docentes cada vez mais interessados na temática e que buscam a todo momento o aprendizado bem como formas lúdicas de trabalhar com o material.

A chegada na Escola São Francisco de Assis, localizada na Rua 13, número 220, foi acompanhada diretamente pela então professora coordenadora do Departamento de Cultura de Canapolis que compunha outro cargo como vicediretora da Escola. A escola extremamente organizada contava com clima amistoso pela ânsia da busca do conhecimento. Isso se efetivou de tal forma aos nossos olhos que as alunas e alunos que iriam participar da oficina de educação patrimonial com o recorte para a temática indígena - estavam fora do seu turno e rotina escolar. Além disso, alunos do 3ํano do Ensino Médio com o objetivo de complementar sua carga horária e de aprender um pouco mais para o Vestibular da UEU participaram ativamente da oficina junto as alunas e alunos do 6ㅇ ano do Ensino Fundamental.

Diante dessa peculiaridade a "oficina de educação patrimoniali reflexões e diálogos sobre a história indígena da região" teve sua metodologia modificada. Isto porque o nosso público alvo era estudantes do ensino fundamental e a inscrição dos alunos do Ensino Médio trouxe uma nova roupagem para o ambiente de ensinoaprendizagem. Assim, abrimos a eles a possibilidade de uma dialogicidade em intervenções pontuais, mas sem que estas adentrassem em terrenos teóricos ainda não vistos pelos discentes e pelas discentes do ensino fundamental.

Feito essas ressalvas, houve a apresentação da turma, da equipe de educação patrimonial e das professoras. A luz desse momento de trocas e saberes houve a filmagem e captação de expressões, gestos e olhares para a composição do documentário.

A turma apresentou-se bastante participativa e inteirada da ocupação indígena na região. Sua professora de História que estava presente na oficina havia dado no bimestre anterior eixos que versavam sobre Antropologia. História e Arqueologia da região. Nesse sentido, as imagens selecionadas para incitar as alunas e alunos a reproduzir estereótipos e naturalizações acerca dos grupos indígenas assumiu um papel reverso. Ou seja, as alunas e alunos do $6^{\circ}$ ano não achavam 
possível que os estávamos questionando sobre a dinamicidade da cultura dos grupos indígenas. Esse questionamento não assumiu o formato de crítica ao nosso trabalho, mas foi feito a partir da incredulidade ou obviedade que nossos apontamentos (propositais) causavam neles.

Parece-nos correto dizer que a postura de desnaturalização já fora realizada dentro dos muros escolares pelo grupo de professores. Esse despertar lançou na equipe de educação, euforia e entusiasmo, de tal modo que a oficina passou a ser uma roda de conversa, ou círculo de cultura onde a orquestra não estava sendo regila por um maestro, mas pela sinfonia dos ritmos e timbres evocadas pela simetria do conhecimento. Após esses diálogos e provocações, apresentamos o conceito de etnogênese ${ }^{16}$ como uma alternativa conceitual a ser utilizada na sala de aula do $3^{\circ}$ ano de Ensino Médio.

Em momento posterior foì realizada a oficina de grafísmos indígenas para apresentar a dinamicidade da cultura associada a manutenção das identidades dos grupos. A oficina assumiu um caráter lúdico e extrovertido. As alunas e alunos constantemente perguntavam o que cada símbolo significava na tentativa de registrar aquilo que estava sendo gravado em suas peles. A ansiedade para contar aos pais, irmãos, tios e avos era representada pela inquietude nas cadeiras onde fora realizada as pinturas. Esse exercícío estimulou não só a vontade de aprender mais sobre o patrimônio de sua região, mas sobretudo sobre a valorização e o respeito a diversidade.

Interessante notar que estes relatos, quando feito a luz de um texto científico pode reduzir a complexidade das situações e eventos vivenciados pela equipe. Por isso que ao fim desse tomo, cabe ressaltar que, progressivamente a realização das visitas, dos encontros e do desenvolvimento das atividades, a equipe de educação patrimonial acabou por se inserir no universo de pesquisa, no qual o produto mais ilustrativo foi a recepção por parte da Casa de Cultura de Canápolis e a incredulidade das alunas e alunos diante de algo obvio para seu universo de conhecimento; e das palavras de um famoso tocador de viola de Monte Alegre de Minas que peremptoriamente e assertivamente agradeceu o trabalho que estávamos desenvolvendo, isso pois, um dos pilares era a valorização da cultura raiz bem como o da sua viola caipira. Esses dois eventos acabavam por nos inserir e nos afetar dentro do universo de pesquisa.

A noção de afeto pode ser compreendida nas palavras da antropóloga francesa Favret- Saada: "quando se está em um tal lugar, é-se bombardeado por intensidades específicas (chamemo-las de afetos), que geralmente não são

16 ARRUTI, J. M. P Andion. Etnogêneses Indigenas. In. Povos Indígenas no Brasil. São Paulo: Instituto Socioambiental. 2006. 
significáveì ${ }^{\text {"17 }}$. Na investigação científica, houve confraternizações, diálogos, trocas de saberes, práticas e aprendizados que ao nosso ver podem ser compreendidas, enquanto intensidades específicas acidentáveis ${ }^{18}$

Ser afetada ${ }^{19}$ é uma imersão quase completa no universo de pesquisa. Neste sentido, quase todas as intensidades específicas foram naturalizadas nas nossas mentes e passaram então a não ser significáveis do ponto de vista científico. Nos sentimos "imersos" na cultura. Em outras palavras, a disposição física e intelectual dos sujeitos, o ambiente dos municípios, o encontro com as pessoas e o acesso as suas memórias naturalizadas e não significáveis.

Cabe enunciar uma diferença conceitual apontada pela autora20, "aceitar 'participar' e ser afetado não tem nada a ver com uma operação de conhecimento por empatia", ou seja, não é se por no lugar do outro, da alteridade. Ser afetada é algo que transcende a empatia. $\bigcirc$ cientista, orientado pelo processo empático, se coloca no lugar do nativo, alicerçado por um serie de preceitos científicos, objetivando registrar o discurso social. Porém, quando imerso, afetado em uma dada cultura, as suas experiências, ocasiões e situações inerentes ao processo de pesquisa se tornam inenarráveis, impossíveis de serem reelaboradas intelectualmente, na rememoração dos fatos.

Esse duplo processo de imersão e afeto corroboram para o desenrolar das atividades bem como pelo aceite das Escolas, alunas e alunos, professoras e professores e de toda a comunidade em nos receber e ofertar tudo aquilo que julgássemos necessário para o sucesso de nosso trabalho

17 FAVRET-SAADA, Jeanne. "Ser afetado", de Jeanne Favret-Saada. Cadernos de Campo, n. 13, PPGAS/FFLCH-USP p. 155-161. São Paulo, jan. 2005, p.159.

18 Entendemos por intensidades específicas acidentáveis, algo não previsto no processo de pesquisa, específica pois envolve a singularidade do discurso social dos sujeitos pesquisados. Segundo Geertz (1978), a significação do mesmo só pode ser compreendida em sua totalidade significável apenas pelo sujeito e não na apreensão científica do pesquisador. Na nomenclatura dada à situação de pesquisa, entendo por acidentável algo não premeditado e peculiar em uma situação específica concreta.

19 Idem.

${ }^{20}$ Idem, p. 158. 


\section{por uma etno\&ênese nas ações educativas}

$\bigcirc$ desenvolvimento metodológico da educação patrimonial pode ser praticado no ambiente formal de ensino (escolas) ou informal (comunidade, associações de bairro, museus, parques ambientais) e também se adequar a qualquer tipologia de patrimônio21.

Os procedimentos metodológicos adotados para a execução deste trabalho consistiram então no oferecimento da "Oficina de educação patrimonial reflexões e diálogos sobre a história indígena da região" dentro da Escola Estadual Márcia Caetano Alves, no município de Canápolis e Escola Estadual São Francisco de Assis, no município de Monte Alegre de Minas.

Como dito anteriormente, a linha diretiva foi baseada inicialmente em provocações feitas nessas crianças por meio de indagações sobre o que é Patrimônio, sobre o conhecimento histórico da região, e se já tinham ouvido falar de grupos indígenas. Estávamos preparadas para encontrar um completo desconhecimento por parte do corpo docente e discente, entretanto, e indo à revelia do esperado, as alunas e alunos e também as professoras que participaram da atividade deram indícios de que o protagonismo indígena na região está sendo cada vez mais acionado, refletido e trabalhado com as alunas e alunos. Tal empreendimento ficou nítido no interesse das professoras em ter acesso ao produto final da equipe que seria a cartilha junto ao documentário.

A apresentação do material foi regada com um tom de humor e baseada em imagens e estereótipos de indígenas com o único objetivo de despertar nesses discentes a válvula da desnaturalização. Estes indivíduos, quando imersos em uma dada cultura, naturalizam o discurso social, muitas vezes, baseado nas apreensões interpretativas de memorialistas e bandeirantes que ao chegarem no sertão da Farinha Podre depararam-se com populações que cá já faziam morada. Nesse ponto, construirão imagens umbráticas que elevaram a população branca em cima da depreciação de negros e indígenas da região22. $\bigcirc$ nosso trabalho, portanto, foi o de realizar o papel reverso, isto é, "desnaturalizar" os comportamentos sociais frente as imagens e estereótipos dos principais moradores históricos da região. Para isso, a

21 TEIXEIRA, Claudia Adriana Rocha. A EDUCAÇÃo PATRIMONIAL NO ENSINO DE HISTÓRIA. Biblos, Rio Grande, 22 (1): 199-211, 2008.

22 AMANTINO, Márcia. O mundo das feras: Os moradores do SERTÃO OESTE DE MINAS GERAIS - século XVIII. 2001. 426 f. Tese (Doutorado em História) - Instituto de Filosofia e Ciências Humanas, Universidade Federal do Rio de Janeiro, Rio de Janeiro, 2001. ALVES, Daniella Santos. Do Alto do Espia: Gentios, Calhambolas e Vadios no sertão do Campo Grande - século XIX. Dissertação (mestrado), Universidade Federal de Uberlândia (UFU), MG, 2017. 
oficina foi feita sob dois primas: uma parte teórica e uma parte prática que foi a realização dos grafismos indígenas.

Esses dois processos feito a sua justa medida e, em conjunto com o já trabalhado por nós, permitiu que os as alunas e alunos avançassem na ideía de que as populações indígenas não estão associadas a grupos silvícolas e hostis. Estes, por seu turno, vivem, muitas vezes, em conjunto com a nossa sociedade e continuam a construir e reproduzir suas identidades e expressões tradicionais. Diante desse quadro, provocávamos nas alunas e alunos, obviamente que, respeitando seu vocabulário e idade, o conceito de etnogênese

A ideia de "emergências"23, "ressurgimentos", ou "viagens da volta", representa o que a Antropologia desde os anos 1970 passa a conceituar como processo de etnogênese. Esse é o termo que faz alusão ao processo que marca a constituição de novos grupos étnicos a partir do contato, choque, migração, dizimações que os grupos tenham sofrido no seu processo histórico. Por isso é importante enfatizar que ao falar em etnogênese não estamos nos referindo a um grupo especifico de indígenas, mas a um processo social presente nas várias regiões do Brasil.

Processo similar aconteceu na região que hoje compreende o Triângulo Mineiro e Alto Paranaíba, no século XVIII. Esta região foi habitada pelos índios Kayapó cuja perpetuação histórica foi marcada pelos intensos contatos com a frente colonial, suscitando assim sua morte e não resistência. Castelnau, em meados do século XIX, viajando pelo interior do Brasil, constatou que os Gradaú, um povo habitante ao norte da ilha Bananal, seriam um subgrupo Kayapó comprovando assim, não sua morte, mas suas resistências24. Tais estudos baseados na hipótese de continuidade da cultura Kayapó foram fundamentais para outros autores avançarem nas pesquisas sobre esse grupo e, quiçá, na possível existência de remanescentes adentrando o século XX.

Nesse sentido, através dos recentes estudos etnográficos que se observam essas nuances interpretativas. Segundo Giraldin25, foi o antropólogo Richard H. Heelas, em 1979, que apresentou a primeira hipótese de que os Panará - da região norte do Mato Grosso, nas margens do rio Peixoto de Azevedo - e os Kayapó poderiam ser de um único grupo. Sua proposição foi ratificada pela lista de termos cognatos entre Panará e Kayapó feita por Saint-Hillaire e Pohl no aldeamento goiano

\footnotetext{
${ }^{23}$ ARRUTI, J. M. P Andion, op. cit.
}

${ }^{24}$ GIRALDIN, Odair. Cayapó e Panará. Luta e sobrevivência de um povo Jê no Brasil Central. Campinas, Editora da Unicamp, 1997.

\section{Ibidem.}


São José de Mossâmedes, no princípio do século XIX. $\bigcirc$ segundo trabalho antropológico sobre os Panará foì feito por Schwartzman, em 1980, além dos dados coletados a priori por Pohl e Saint-Hilaire, Schwartzman apresentou novas evidências da possível relação dos Panará com os Kayapó, tendo como base a proximidade de algumas técnicas e modos de contato com o mundo exterior.

documento redigido por Alexandre de Souza Barbosa, no início do século XX, designadamente em 1911, permite avançar na hipótese desses autores supracitados. Alexandre de Souza Barbosa consegue alguns dados etimológicos e linguísticos, compilando assim, um dos maiores vocabulários sobre a língua Kayapó, composto por um conjunto de mais de setenta (70) palavras, além de obter algumas descrições sobre o modo de realização da caça e da pesca26. $\bigcirc$ material levantado sobre a proximidade entre Panará e Kayapó, nos possibilitita, então, lançar fecundas tintas sobre a permanência desse grupo no século XX e não sua dizimação como afirmavam alguns autores.

A dificuldade de explicar esse processo de etnogênese para as professoras, alunas e alunos, e qualquer ouvinte e interessado na questão não está relacionado a distância que possam estar da Antropologia ou dos documentos históricos. A dificuldade repousa na ideia reiterada pelo senso comum de que índios "misturados" ou em processo de etnogênese são índios de segunda mão ou menos índios. E isso só acontece porque ainda temos no nosso imaginário social a ideia de que grupo étnico é uma simples derivação de etnia e dentro dessa palavra logo nos recobre a mente a pureza de uma raça e de uma cultura extremamente distinta (ARRUTI, 2006). A resolução desses percalços estaria no uso moderado e relativizado do conceito de etnicidade.

A etnicidade27 é uma forma de organização social, baseada na atríbuição categorial que classifica as pessoas em função de sua origem suposta (grifo nosso), que se acha validada na interação social pela ativação de signos culturais socialmente diferenciadores. Assim, grupos em etnogênese acionam seus elementos contrastivos e diferenciadores diante de práticas ancestrais, revelando tanto sua mudança cultural no plano histórico, mas ratificando sua identidade étnica no plano político, social e com outros grupos em contato. Esse processo altamente complexo e de difícil apreensão, foi apresentado as alunas e aos alunos no decorrer da ofícina por intermédio, como dito, das imagens e reflexões diante dos aspectos e exemplos de sua vida cotidiana, mas também por um elemento que consideramos central em tal inserção, a oficina de grafísmos indígenas.

\section{${ }^{26}$ Ibidem.}

${ }^{27}$ BARTH, Frederik. “Introducción”. In: F. Barth (org.), Los grupos étnicos y sus fronteras. México: Fondo de Cultura Económica, 1969. 


\section{3}

Essa oficina teve como centralidade exemplificar as alunas e alunos e tornar mais palatável as discussões sobre as mudanças que podem ocorrer nas culturas indígenas. Desse modo, mostramos populações que vivem com uma proximidade significativa com o mundo não índio e ainda assim utilizam de elementos de seus antepassados para se comunicar, como é o caso dos grafismos corporais indígenas.

Ogrupo que apresentamos é da etnia Pataxó, que residem na aldeia de Coroa Vermelha e Reserva da Jaqueira, localizada a oito quilômetros ao sul de Santa Cruz Cabrália e quinze quilômetros ao norte de Porto Seguro28. As imagens representadas faziam menção as categorias e organizações sociais feitas por esses grupos. Nos desenhos feitos nos braços mostramos a presença de uma barra em formato horizontal que representa o Deus Txôpai, logo acima mostramos mais três barras que designava as aldeias da qual os grupos faziam parte.

Ao fim da oficina realizamos uma pintura corporal com o intuito de torna a atividade menos abstrata e mais lúdica e concreta. $\bigcirc$ resultado atingiu nossas expectativas, pois, num único evento trabalhamos dois conceitos chaves que permeia as principais discussões sobre indigeníssimo no Brasil. Ao mesmo tempo que mostramos a mudança que esses grupos sofrem no processo histórico (etnogênese), mostramos também que eles mantem sua identidade, através do que Barth vem chamar de etnicidade, pois, vivem próximo ao mundo não-indígena e continuam a construir e a perpetuar elementos contrastivos e afirmativos de sua cultura através dos grafismos. Percebemos que a compreensão significativa dos símbolos dessa cultura despertou nas alunas e alunos a válvula do relativismo cultural e da importância histórica de todos os grupos sociais independentes de quais são.

\section{considerações finais}

A possibilidade da experimentação etnográfica nos municípios de Canápolis e Monte Alegre de Minas permitiu em nós antropólogas a prática de se envolver com nossos sujeitos de trabalho. Essa imersão proporcionou um despertar do saber e a localização de patrimônios materiais e imateriais destes municípios nas alunas e alunos e nas educadoras e educadores das escolas.

28 PREDEZ; ZORZO. Hamykahay- Expressão Gráfica Corporal Pataxó. In. XX Simpósio Nacional de Geometria Descritiva e Desenho Técnico. Rio de Janeiro, 2011. 
Nesse sentido, a educação patrimonial permitiu que a comunidade valorizasse ainda mais sua identidade e cultura. Estas, por seu turno, devem ser entendidas como múltiplas e dinâmicas uma vez que essa relação de pertencimento faz com que o indivíduo se reconheça como parte de determinada teia cultural e identitária construídas, muitas vezes, de forma involuntária no seu dia-a-dia. A consequência de tal processo é a produção do conhecimento, apropriação e valorização de sua herança cultural, capacitando-os para um melhor usufruto destes bens, e propiciando a geração a produção de novas percepçães e analises críticas dentro de um processo contínuo de criação cultural.

As ações educativas deram conta de um processo centrado no patrimônio cultural como fonte primária de conhecimento e enriquecimento individual e coletivo. $\bigcirc$ conhecimento crítico, bem como a apropriação consciente pelas comunidades do seu patrimônio são fatores indispensáveis no processo de preservação sustentável desses bens.

projeto permitiu ainda uma transformação na maneira de se ver e tratar - patrimônio cultural ao trazer para o debate o protagonismo indígena na região que ainda é muito silenciado, buscando um constante aperfeiçoamento nas formas de suscitar os diálogos e reflexões para a comunidade visando sensibilizar e despertar no público a relevância do reconhecimento, valorização e conservação do patrimônio cultural.

Por fim, vale destacar ainda que a produção filmográfica, bem como a cartilha elaborada por nós, se transformou em material que é utilizado agora pela prefeitura e pelas escolas para propagar reflexões acerca do patrimônio das cidades. As mídias, por serem didáticas e por terem um alcance amplo serve tanto a crianças, servidores e docentes, já que conta com a colaboração de profissionais conceituados na temática da educação patrimonial que assiste às discussões tão frequentes na cidade e que auxiliam assim no resgate do sentimento de pertencimento e preservação às referências culturais locais. 